\title{
Incidental extraction of a temporary epicardial pacemaker wire with right ventricular perforation during endomyocardial biopsy
}

\author{
Boško Skorić*, Željko Baričević, Jana Ljubas, Maja Čikeš, Davor Miličić \\ University of Zagreb School of Medicine, University Hospital Centre Zagreb, Zagreb, Croatia
}

Introduction: Endomyocardial biopsy (EMB) is a relatively safe procedure. Nevertheless, cardiac perforation may occur and can be lethal. It is a real challenge how to manage this clinical urgency. We present a case of a heart transplant patient who suffered right ventricular (RV) perforation as a consequence of an incidental extraction of a temporary epicardial pacemaker wire.

Case report: A 51-year-old patient was admitted for a routine control EMB three months after the heart transplantation. Using Seldinger technique, we introduced a long sheath (7-French) into the RV. Cordis bioptome $(2.2 \mathrm{~mm}$ jaw) was introduced through the sheath. The jaws of the bioptome were opened and gentle forward pressure was maintained while the jaws were closed. The bioptome was then removed by traction. The initial resistance suddenly vanished and the bioptome leapt into the sheath. To our surprise, the jaws of retracted bioptome held a piece of temporary epicardial pacing wire retained from the previous cardiac surgery. The patient was asymptomatic, but nonetheless we assumed that there was a perforation of the RV free wall with the long sheath sealing the perforation at the same

Received: $27^{\text {th }}$ Apr 2014

*Address for correspondence: Klinički bolnički centar Zagreb, Kišpatićeva 12, HR 10000 Zagreb, Croatia.

Phone: +385-95-3959-910

E-mail: bskoric3@yahoo.com time. We gave iodine contrast through the sheath and the extravasation of the contrast into the pericardial space was seen. With cardiac surgery back-up and under both fluoroscopic and ultrasound surveillance we pulled out the sheath without any symptoms, hemodynamic changes or development of pericardial effusion.

Discussion: The rate of RV perforation caused by a bioptome catheter during EMB is $0.05-5 \%$ and leads to tamponade in less than a half of the cases. The mortality is low and the majority of perforations can be managed without pericardiocentesis and/or a surgery accompanied by careful patient monitoring. The withdrawal of the perforating catheters seems to be dangerous if the perforation occurs with a delay or when the symptoms of the cardiac tamponade appear before the withdrawal. Despite the fact that the sheath was 7 Fr large, its withdrawal went without tamponade, probably due to the normal RV muscle wall, pericardial adhesions to the myocardium after cardiac surgery and a very short time the sheath was left at the perforation site. The risk is lower three months after the cardiac surgery by which time the pericardial adhesions to the myocardium should be formed. To our knowledge, this is the first case of myocardial perforation caused by incidental extraction of a temporary epicardial pacemaker wire as a complication of EMB.

KEYWORDS: cardiac allograft vasculopathy, percutaneous coronary intervention.

CITATION: Cardiol Croat. 2014;9(5-6):237. 